JURNAL RESPIRASI

JR

Vol. 4 No. 3 September 2018

\title{
Gambaran Radiografi Tuberkulosis Paru Multidrug-Resistant: Studi Retrospektif di Rumah Sakit Umum Dr. Soetomo Surabaya
}

\author{
Stephanie Christina Sulaiman ${ }^{1}$, Lulus Handayani ${ }^{1}$, M. Yamin S.S. ${ }^{1}$, Soedarsono ${ }^{2}$ \\ ${ }^{1}$ Departemen Radiologi, Fakultas Kedokteran, Universitas Airlangga/RSUD Dr. Soetomo \\ ${ }^{2}$ Departemen Pulmonologi dan Ilmu Kedokteran Respirasi, Fakultas Kedokteran, Universitas Airlangga/RSUD Dr. Soetomo
}

\begin{abstract}
Background: Multidrug-resistant pulmonary tuberculosis (MDR-TB) is a major health problem worldwide. Prompt diagnosis is necessary for insuring appropriate therapy to lower morbidity and mortality, as well as to prevent disease transmission. Determination of drug-resistance patterns through microbiological examination is sometimes challenging, especially when the sputum acid-fast bacilli smear is negative. Therefore, it is worthwhile to investigate whether there may be radiographic patterns suggesting MDR-TB infection. The objective of this study was to evaluate the radiographic features of MDR-TB. Methods: From September 2015 to March 2018, 167 patients with microbiologically proven MDR-TB were enrolled in the study. All radiographs were obtained before the patients received MDR-TB chemotherapy regimen. Posterior-anterior chest radiography was performed using digital radiography system (Hitachi Radnext50 500mAs) and retrospectively reviewed as digital raw data. Results: Based on severity category, $60 \%$ had severe lesion, $31 \%$ had moderate lesion, and only $9 \%$ had mild lesion. The most frequently observed findings were ground glass opacity or consolidation, noted in $96 \%$ patients, with bilateral lung involvement in $81 \%$ patients; fibrosis (95\%), cavity (78\%; 87\% of which were multiple), interstitial opacities (53\%), pleural thickening and mediastinal shift (59\%). Other radiological findings were calcification (16\%), emphysema (13\%), lung destruction (12\%), atelectasis (10\%), nodule (8\%), bullae (8\%), bronchiectasis (5\%), miliary pattern (1\%), pleural effusion (25\%), pneumothorax (1\%), and hilar lymphadenopathy (14\%) which predominantly unilateral. Conclusion: The presence of severe pulmonary lesion, ground glass opacity or consolidation with bilateral lung involvement, fibrosis, multiple cavities, interstitial opacities, pleural thickening, and mediastinal shift are the main features of MDR-TB.
\end{abstract}

Keywords: tuberculosis, multidrug-resistant, radiograph, $X$-ray

Correspondence: Stephanie Christina Sulaiman, Departemen Radiologi, Fakultas Kedokteran, Universitas Airlangga/RSUD Dr. Soetomo. Jl. Mayjen Prof. Dr. Moestopo 6-8 Surabaya 60286. E-mail: christinasulaiman7@ gmail.com

\section{PENDAHULUAN}

Tuberkulosis (TB) merupakan penyebab kematian ketiga tertinggi akibat infeksi di dunia. Menurut Organisasi Kesehatan Dunia (WHO), TB telah menginfeksi sekitar sepertiga populasi dunia dengan perkiraan 1,5 juta kematian setiap tahun.,

TB paru resisten obat (TB paru MDR) didefinisikan sebagai infeksi Mycobacterium tuberculosis (MTB) yang resisten terhadap setidaknya isoniazid dan rifampisin, dengan atau tanpa resistensi tambahan terhadap satu atau lebih obat antituberkulosis lini pertama. WHO memperkirakan ada 6.800 kasus TB MDR baru di Indonesia setiap tahun, yang menempatkan Indonesia sebagai negara ke-8 dengan kasus TB MDR terbanyak di dunia., ${ }^{2,3}$
Penegakan diagnosis yang cepat diperlukan untuk inisiasi terapi, sehingga dapat menurunkan morbiditas dan mortalitas serta mencegah transmisi penyakit lebih lanjut. Namun, penentuan pola resistensi obat melalui pemeriksaan mikrobiologi terkadang tidak mudah dilakukan, terutama ketika pemeriksaan apus sputum Batang Tahan Asam (BTA) menunjukkan hasil yang negatif. ${ }^{4}$ Oleh karena itu penting untuk mengevaluasi spektrum dan pola gambaran radiologis pada TB paru MDR sebagai penunjang dalam penegakan diagnosis. Radiografi toraks lebih banyak digunakan di negara berkembang karena ketersediaannya yang luas dan biayanya yang relatif terjangkau. Tujuan dari penelitian ini adalah untuk mendeskripsikan profil radiografi toraks pada TB paru MDR. 


\section{METODE}

Penelitian ini dilakukan secara retrospektif di Departemen Radiologi, RSUD Dr. Soetomo Surabaya, Indonesia, menggunakan data sekunder yang diperoleh dari rekam medis pasien dari bulan September 2015 hingga Maret 2018. Protokol penelitian telah disetujui oleh Komite Etik RSUD Dr. Soetomo Surabaya, Indonesia.

Sejumlah 167 pasien TB paru MDR dimasukkan dalam penelitian. TB paru MDR didefinisikan sebagai TB paru yang disebabkan oleh kuman yang resisten terhadap setidaknya isoniazid dan rifampisin, dengan atau tanpa resistensi tambahan terhadap satu atau lebih obat anti-tuberkulosis lini pertama. Diagnosis TB MDR dikonfirmasi dengan hasil tes apus sputum BTA dan kultur dari data rekam medis.

Semua radiografi diperoleh sebelum pasien menerima rejimen kemoterapi TB paru MDR. Radiografi toraks proyeksi posterior-anterior dilakukan menggunakan sistem radiografi digital (Hitachi Radnext50 500mAs) dan dievaluasi dalam bentuk raw data digital, oleh seorang dokter spesialis radiologi konsultan divisi kardiotoraks dan seorang residen radiologi senior.

Radiografi toraks dievaluasi untuk beberapa parameter yang mencakup lesi pada parenkim paru, lesi pleura, dan lesi mediastinum. Data demografi dan adanya faktor risiko pada semua pasien TB paru MDR juga dievaluasi. Data yang diperoleh ditabulasikan dan diolah menggunakan IBM SPSS Statistics for Windows, Versi 21.0.

\section{HASIL}

\section{Data demografi pasien}

Selama bulan September 2015 hingga Maret 2018, 167 pasien TB paru MDR dimasukkan ke dalam penelitian ini. Dari 167 pasien, 93 (56\%) pasien adalah laki-laki dan 74 (44\%) pasien adalah perempuan. Usia rata-rata semua pasien adalah 45,62 $\pm 12,24$ tahun dan rentang usia 15-75 tahun. Distribusi usia yang paling banyak didapatkan adalah kelompok usia 46 - 55 tahun (36,5\% pasien). Berdasarkan pengukuran indeks massa tubuh, $91(54,5 \%)$ pasien termasuk dalam kategori berat badan normal, $73(43,7 \%)$ pasien berat badan kurang (underweight), dan $3(1,8 \%)$ pasien berat badan lebih (overweight). Data demografi pasien dirangkum dalam Tabel 1.

\section{Faktor risiko}

Dari 167 pasien, 49 (29,3\%) pasien mempunyai faktor risiko untuk menderita penyakit tuberkulosis paru. Faktor risiko yang paling banyak didapatkan adalah merokok, ditemukan pada 41 (25\%) pasien; faktor risiko lain yang teridentifikasi adalah diabetes mellitus pada 8 pasien (4,8\%); dan HIV/ AIDS pada 1 pasien $(0,6 \%)$.

\section{Temuan pada radiografi toraks}

Berdasarkan derajat keparahan lesi, $100(60 \%)$ pasien menunjukkan lesi yang berat, 52 (31\%) pasien menunjukkan lesi sedang, dan hanya 15 (9\%) pasien yang menunjukkan lesi ringan. Radiografi toraks dinilai untuk 11 parameter lesi parenkim paru yang meliputi ground-glass opacity dan konsolidasi, kavitas, interstitial opacities, nodul, miliary pattern, fibrosis, kalsifikasi, bula, emfisema, bronkiektasis, atelektasis; 5 parameter lesi pleura yaitu efusi pleura, penebalan pleura, kalsifikasi pleura, pneumotoraks, fluidopneumothorax; dan 3 parameter lesi mediastinum antara lain limfadenopati hilus, limfadenopati mediastinum, dan pergeseran mediastinum. Temuan paling umum pada radiografi toraks adalah ground-glass opacity, didapatkan pada 161 (96\%) pasien, dengan keterlibatan paru bilateral pada 131 (81\%) pasien; terletak di zona atas paru pada 150 (93\%) pasien, zona tengah paru pada 143 (89\%) pasien, dan zona bawah paru pada 127 (79\%) pasien. Temuan lain yang paling sering diamati adalah fibrosis, yang didapatkan pada 158 (95\%) pasien, kavitas pada $131(78 \%)$ pasien $(87 \%$ di antaranya multipel), interstitial opacities pada $88(53 \%)$ pasien, penebalan pleura pada $98(59 \%)$. \%) pasien, dan pergeseran mediastinum pada $98(59 \%)$ pasien. Temuan radiologis lainnya adalah kalsifikasi (16\%), emfisema $(13 \%)$, atelektasis $(10 \%)$, nodul $(8 \%)$, bula $(8 \%)$, bronkiektasis $(5 \%)$, miliary pattern $(1 \%)$, efusi pleura (25\%), fluidopneumotoraks $(2 \%)$, pneumotoraks $(0,6 \%)$,

Tabel 1. Karakteristik demografi pada 167 pasien dengan TB paru MDR

\begin{tabular}{|c|c|}
\hline Data Demografi & Jumlah Pasien (\%) \\
\hline \multicolumn{2}{|l|}{ Jenis kelamin } \\
\hline Laki - laki & $93(56)$ \\
\hline Perempuan & $74(44)$ \\
\hline \multicolumn{2}{|l|}{ Usia } \\
\hline $15-25$ tahun & $10(5,9)$ \\
\hline $26-35$ tahun & $26(15,6)$ \\
\hline $36-45$ tahun & $38(22,8)$ \\
\hline $46-55$ tahun & $61(36,5)$ \\
\hline $56-65$ tahun & $26(15,6)$ \\
\hline $66-75$ tahun & $6(3,6)$ \\
\hline Rerata \pm SD & $45,62 \pm 12,24$ \\
\hline \multicolumn{2}{|l|}{ Indeks massa tubuh } \\
\hline Berat badan kurang & $73(43,7)$ \\
\hline (underweight) & $91(54,5)$ \\
\hline Berat badan normal & $3(1,8)$ \\
\hline $\begin{array}{l}\text { Berat badan lebih } \\
\text { (overweight) }\end{array}$ & - $(0)$ \\
\hline Obesitas & \\
\hline
\end{tabular}


dan limfadenopati hilus (14\%) yang sebagian besar unilateral. Ringkasan temuan radiologi disajikan pada Tabel 2.

Tabel 2. Distribusi temuan radiografi toraks pada 167 pasien dengan TB paru MDR

\begin{tabular}{|c|c|}
\hline Temuan Radiografi Toraks & Jumlah Pasien (\%) \\
\hline \multicolumn{2}{|l|}{ Lesi parenkim paru } \\
\hline \multicolumn{2}{|l|}{ Lokasi } \\
\hline zona atas & $150(93)$ \\
\hline zona tengah & $143(89)$ \\
\hline zona bawah & $127(79)$ \\
\hline \multicolumn{2}{|l|}{ Lateralitas } \\
\hline unilateral & $30(19)$ \\
\hline bilateral & $131(81)$ \\
\hline Kavitas & $131(78)$ \\
\hline \multicolumn{2}{|l|}{ Jumlah } \\
\hline 1 (tunggal) & $17(13)$ \\
\hline$>1$ (multipel) & $114(87)$ \\
\hline \multicolumn{2}{|l|}{ Diameter terbesar } \\
\hline$<2 \mathrm{~cm}$ & $70(53)$ \\
\hline $2-4 \mathrm{~cm}$ & $44(34)$ \\
\hline$>4 \mathrm{~cm}$ & $17(13)$ \\
\hline \multicolumn{2}{|l|}{ Derajat keparahan lesi } \\
\hline Ringan & $15(9)$ \\
\hline Sedang & $52(31)$ \\
\hline Berat & $100(60)$ \\
\hline $\begin{array}{l}\text { Interstitial opacities (reticular/ } \\
\text { nodular/ reticulonodular pattern) }\end{array}$ & $88(53)$ \\
\hline Nodul & $14(8)$ \\
\hline \multicolumn{2}{|l|}{ Jumlah } \\
\hline 1 (tunggal) & $10(71)$ \\
\hline$>1$ (multipel) & $4(29)$ \\
\hline Miliary pattern & $2(1)$ \\
\hline Fibrosis & $158(95)$ \\
\hline Kalsifikasi & $27(16)$ \\
\hline Bula & $13(8)$ \\
\hline Emfisema & $21(13)$ \\
\hline Bronkiektasis & $9(5)$ \\
\hline Atelektasis & $16(10)$ \\
\hline \multicolumn{2}{|l|}{ Lesi pleura } \\
\hline Efusi pleura & $42(25)$ \\
\hline Penebalan pleura & $98(59)$ \\
\hline Kalsifikasi pleura & $-(0)$ \\
\hline Pneumotoraks & $1(0,6)$ \\
\hline Fluidopneumotoraks & $3(2)$ \\
\hline \multicolumn{2}{|l|}{ Lesi mediastinum } \\
\hline Limfadenopati hilus & $24(14)$ \\
\hline \multicolumn{2}{|l|}{ Lateralitas } \\
\hline unilateral (kanan) & $14(58)$ \\
\hline unilateral (kiri) & $6(25)$ \\
\hline bilateral & $4(17)$ \\
\hline Limfadenopati mediastinum & $-(0)$ \\
\hline Pergeseran mediastinum & $98(59)$ \\
\hline Trakea & $73(44)$ \\
\hline Hilus & $69(41)$ \\
\hline Jantung & $28(17)$ \\
\hline Diafragma & $4(2)$ \\
\hline
\end{tabular}

\section{PEMBAHASAN}

Distribusi jenis kelamin menunjukkan bahwa TB paru MDR lebih banyak didapatkan pada laki-laki (56\%) dibandingkan perempuan $(46 \%)$. Hal ini konsisten dengan hasil penelitian sebelumnya yang dilakukan oleh Kim W. dkk, di mana ditemukan bahwa TB paru MDR lebih sering diamati pada laki-laki $(61 \%)$ dibandingkan perempuan $(39 \%)$. Dalam penelitian ini, proporsi lakilaki lebih banyak, hal ini dikaitkan dengan salah satu faktor risiko yang paling umum yaitu merokok, di mana semua pasien yang memiliki kebiasaan merokok dalam penelitian ini adalah laki-laki. ${ }^{5}$ Rentang usia pasien adalah 15-75 tahun, dengan usia rata-rata 45,62 tahun, dan distribusi tertinggi dalam kelompok usia 46-55 tahun. WHO pada tahun 2013 menyatakan bahwa sebagian besar pasien TB berusia produktif. Tingkat mobilitas dan interaksi sosial yang tinggi di usia produktif menyebabkan prevalensi TB yang lebih tinggi karena meningkatnya risiko paparan. ${ }^{6}$ Hasil penelitian menunjukkan bahwa rentang nilai untuk indeks massa tubuh pasien TB paru MDR adalah 11,7 - $26 \mathrm{~kg} / \mathrm{m}^{2}$ dengan nilai rata-rata $19,12 \mathrm{~kg} / \mathrm{m}^{2}$. Dari semua pasien, $43,7 \%$ memiliki berat badan kurang, $54,5 \%$ pasien berat badan normal, $1,8 \%$ pasien berat badan lebih, dan tidak ada pasien dalam kategori obesitas. Hasil serupa diamati dalam penelitian yang dilakukan oleh Cegielski dkk pada tahun 2012, yang menemukan bahwa nilai rata-rata indeks massa tubuh untuk pasien TB paru adalah 21,6 $\mathrm{kg} / \mathrm{m}^{2}$, dengan proporsi pasien berat badan kurang $31,7 \%$, berat badan normal $51,6 \%$, berat badan lebih $13,3 \%$, dan obesitas $3,4 \%$. Selain itu, dalam penelitian itu ditemukan bahwa individu dengan indeks massa tubuh $<18,5 \%$ memiliki hazard ratio (risiko menderita TB) 12,4 kali lebih tinggi daripada individu dengan indeks massa tubuh normal. Status gizi mempengaruhi faktor pejamu dalam hal pembentukan respon imun yang adekuat untuk mencegah infeksi TB. ${ }^{7}$

Faktor risiko yang paling umum dievaluasi adalah merokok, ditemukan pada $25 \%$ pasien. Merokok telah lama dikaitkan dengan peningkatan risiko penyakit TB paru, hasil pengobatan yang buruk, dan risiko reaktivasi TB. Sebuah studi meta-analisis yang dilakukan oleh Michael N. Bates dkk mengungkapkan bahwa risiko relatif untuk terjadinya TB paru pada perokok berkisar antara 1,3 hingga 3,8, dengan peningkatan risiko yang bergantung pada dosis (jumlah rokok per hari dan durasi merokok). Merokok memiliki efek penghambatan ireversibel pada sintase nitrit oksida, enzim yang dibutuh 
kan oleh makrofag alveolar untuk membentuk nitrit oksida untuk menghambat multiplikasi M. tuberculosis. Merokok juga dapat meningkatkan ketersediaan zat besi di saluran napas distal yang dapat mengikat nitrit oksida untuk menghasilkan radikal toksik yang dapat mengganggu fungsi makrofag alveolar. Selain itu, merokok dapat mengurangi kemampuan makrofag alveolar untuk mengaktifkan respons imun yang efektif dengan mengubah ekspresi sitokin pro-inflamasi, menyebabkan limfopenia CD4, dan menyebabkan gangguan mekanis fungsi silia di saluran napas. ${ }^{89}$ Pada evaluasi radiografi toraks, ground-glass opacity (GGO) dan konsolidasi adalah temuan yang paling sering diamati, ditemukan pada $96 \%$ pasien. Temuan ini mirip dengan hasil penelitian yang dilakukan oleh SH Kim dkk yang menyatakan bahwa konsolidasi ditemukan pada $90 \%$ pasien TB paru MDR resistensi primer, serta penelitian yang dilakukan oleh Wooil Kim dkk yang menunjukkan bahwa konsolidasi parenkim adalah ditemukan pada 60-93\% kasus TB paru MDR dengan resistensi sekunder. Hal ini menunjukkan bahwa GGO atau konsolidasi adalah salah satu fitur utama pada TB paru MDR primer dan sekunder, yang merupakan salah satu tanda utama infeksi TB aktif., 5,6

Pada sebagian besar pasien dalam penelitian ini, konsolidasi dikelilingi oleh beberapa opasitas nodular kecil. Hal ini konsisten dengan teori sebelumnya, di mana lesi kecil di sekitar konsolidasi adalah ciri khas TB paru yang membedakannya dari pneumonia karena penyebab lain. ${ }^{10}$ Lokasi GGO yang paling umum dan konsolidasi dalam penelitian ini adalah di zona atas, diikuti oleh zona tengah dan zona bawah. Namun, proporsi ketiga lokasi ini tidak berbeda jauh, karena sebagian besar pasien menunjukkan lesi yang luas pada radiografi toraks yang melibatkan kombinasi dari ketiga zona tersebut. Dalam penelitian ini, sebagian besar GGO dan konsolidasi ditemukan di kedua paru (81\%). Temuan ini mirip dengan hasil pengamatan oleh Jeong A. Yeom dkk pada tahun 2009 yang mengungkapkan bahwa konsolidasi bilateral ditemukan pada $82 \%$ pasien TB paru MDR. Adanya kavitas mungkin berkontribusi pada pola infeksi. Bagian dari kavitas yang telah mengalami likuifaksi bisa masuk ke percabangan bronkus, dan menyebar luas ke bagian paru yang sebelumnya tidak terinfeksi, sebagian karena gravitasi dan mekanisme batuk, dan menyebabkan konsolidasi baru. Oleh karena itu, keterlibatan paru bilateral dengan atau tanpa konsolidasi segmental atau lobar pada TB paru MDR sering terjadi. ${ }^{5,11}$

Kavitas dalam penelitian ini ditemukan pada sebagian besar sampel, sebanyak $78 \%$, dan $87 \%$ di antaranya memiliki kavitas multipel. Kebanyakan pasien menunjukkan gambaran kavitas klasik dengan dinding bagian dalam yang halus dan dikelilingi oleh konsolidasi atau nodul. Hal ini sesuai dengan berbagai literatur yang menyatakan bahwa ada hubungan positif antara adanya kavitas dan TB paru MDR. adanya kavitas merupakan prediktor utama resistensi di samping riwayat pengobatan sebelumnya. Menurut hasil penelitian oleh SH Kim dkk, kavitas ditemukan pada $85 \%$ pasien TB paru MDR. Sementara Hyo-Cheol Kim dkk pada tahun 2004 menyatakan bahwa kavitas multipel ditemukan pada $66 \%$ pasien dengan TB paru MDR. Kavitas terbentuk ketika bagian sentral dari sel epiteloid granuloma mengalami nekrosis kaseosa dan diekstrusi melalui bronkus regional yang terkait. Kesulitan menembus kavitas yang avaskular yang mengandung mikobakteria dalam jumlah besar diyakini sebagai penyebab resistensi. 4,6,11,12,13

Derajat keparahan lesi dinilai berdasarkan sistem penilaian menurut Liping Yan dkk, dengan mayoritas pasien $(60 \%)$ memiliki lesi yang parah, 31\% memiliki lesi sedang, dan 9\% memiliki lesi ringan. Hal ini diyakini terkait dengan durasi penyakit yang lama, serta jumlah kavitas yang lebih banyak dan ekstensi kavitas yang lebih luas pada TB paru MDR. Bagian sentral dari kavitas yang memiliki likuifaksi mengandung mikobakteria dalam jumlah besar dan dapat menyebar ke parenkim paru di sekitarnya melalui bronkus, sehingga lesi parenkim lebih luas. ${ }^{14,15,16,17}$

Interstitial opacities dalam bentuk pola retikular, pola nodular, atau pola retikulonodular, ditemukan pada sejumlah besar sampel dalam penelitian ini, yaitu sekitar $53 \%$ pasien. Temuan serupa juga diamati dalam studi 2009 oleh Jihoon Cha dkk, yang menyatakan bahwa pola retikulonodular ditemukan pada $75 \%$ pasien $\mathrm{TB}$ paru MDR. ${ }^{15}$

Fibrosis parenkim paru didapatkan pada hampir semua pasien dalam penelitian ini (95\%). Fibrosis terbentuk pada tahap kronis penyakit, sebagai bagian dari proses penyembuhan dan remodeling, yang melibatkan peran berbagai sitokin pro-fibrotik yang diregulasi oleh sel TH2 seperti TNF $\alpha$, TGF $\beta$, IL-4, dan IL-13. Selain itu, derajat fibrosis dipengaruhi oleh faktor genetik dan demografi, sebagaimana dinyatakan oleh Dheda dkk (2005) bahwa fibrosis luas terjadi ketika ada respon IFN- $\gamma$ yang poten dan respon imun pejamu didominasi oleh TH2. ${ }^{18,19}$

Penebalan pleura ditemukan dengan proporsi yang lebih tinggi daripada efusi pleura (59\% pasien). Temuan serupa diperoleh dari hasil studi studi yang dilakukan oleh Chung dkk di mana 57\% pasien TB paru MDR menunjukkan penebalan pleura pada radiografi toraks. Temuan ini adalah salah satu tanda kronisitas penyakit. $^{12}$ 
Abnormalitas mediastinum yang paling banyak diamati dalam penelitian ini adalah pergeseran mediastinum, yang merupakan perubahan posisi berbagai struktur mediastinum (trakea, jantung, pembuluh besar atau hilus paru) karena fibrosis di parenkim paru atau pleura. Hasil penelitian ini menunjukkan bahwa pergeseran mediastinum ditemukan pada $59 \%$ pasien. Deviasi trakea ditemukan pada $44 \%$ pasien, elevasi hilus ditemukan pada $41 \%$ pasien, pergeseran posisi jantung ditemukan pada $16,8 \%$ pasien, dan penarikan diafragma ditemukan pada $2 \%$ pasien. Temuan serupa ditemukan dalam studi Icksan dkk (2018), yang menyatakan bahwa pergeseran mediastinum berupa deviasi trakea diperoleh pada $30 \%$ dan elevasi hilus ditemukan pada $35 \%$ pasien. ${ }^{10}$

Keterbatasan penelitian ini adalah penggunaan rekam medis sebagai sumber utama data pasien; sehingga banyak pasien yang tidak dapat diambil sebagai sampel karena data rekam medis yang tidak lengkap.

\section{KESIMPULAN}

Ground-glass opacity dan konsolidasi dengan keterlibatan paru bilateral, fibrosis, kavitas multipel, interstitial opacities, penebalan pleura, dan pergeseran mediastinum adalah gambaran radiografi toraks yang banyak ditemukan pada TB paru MDR. Berdasarkan derajat keparahan, mayoritas pasien TB paru MDR memiliki lesi paru yang berat.

\section{DAFTAR PUSTAKA}

1. Hicks A, Muthukumarasamy S, Maxwell D, Howlett D. Chronic Inactive Pulmonary Tuberculosis and Treatment Sequelae: Chest Radiographic Features. Int $\mathbf{J}$ Tuberc Lung Dis. 2014;18(May 2013):128-33.

2. WHO. Global Tuberculosis Report 2015, 20th Edition. 2015;1-30.

3. M Subuh, Priohutomo S. Pedoman Nasional Pengendalian Tuberkulosis. Jakarta: Kementrian Kesehatan RI; 2014. 6-140 P.

4. Hyo-Cheol Kim, Jin Mo Goo, Hyun Ju Lee, Seong Ho Park, Chang Min Park, Tae Jung Kim J-GI. Multidrug-Resistant Tuberculosis versus DrugSensitive Tuberculosis in Human Immunodeficiency. J Comput Assist Tomogr. 2004;28(3):366-71.

5. Kim W, Lee KS, Kim HS, Koh W. CT and Microbiologic Follow-Up in Primary MultidrugResistant Pulmonary Tuberculosis. Acta Radiol. 2015;0(0):1-8.

6. Kim SH, Min JH, Lee JY. Radiological Findings of Primary Multidrug-Resistant Pulmonary Tuberculosis in HIV-Seronegative Patients. Hong Kong J Radiol. 2014;17:4-8.
7. Cegielski JP, Arab L, Cornoni-Huntley J. Nutritional Risk Factors for Tuberculosis among Adults in the United States, 1971-1992. Am J Epidemiol. 2018;176(5):409-22.

8. Michael N. Bates, Asheena Khalakdina, Madhukar Pai, Lisa Chang, Fernanda Lessa KRS. Risk of Tuberculosis from Exposure to Tobacco Smoke. Arch Intern Med. 2015;167:335-42.

9. Medea Gegia A, Matthew J Magee B, Russell R Kempker C, Iagor Kalandadze D, Tsira Chakhaia A JEG E \& HMB. Tobacco Smoking and Tuberculosis Treatment Outcomes_ A Prospective Cohort Study in Georgia. Bull World Health Organ. 2015;93:390-9.

10. Aziza Ghanie Icksan, Martin Raja Sonang Napitupulu, Mohamad Arifin Nawas FN. Chest XRay Findings Comparison between Multi-DrugResistant Tuberculosis and Drug-Sensitive Tuberculosis Icksan AG, Sonang Napitupulu MR, Nawas MA, Nurwidya F - J Nat Sc Biol Med. Jakarta: CV Sagung Seto; 2008. 2-106 P.

11. Yeom JA, Jeong YJ, Jeon D, Kim PK, Kim CW, Park HK, et al. Imaging Findings of Primary Multidrug-Resistant Tuberculosis: A Comparison with Findings of Drug-Sensitive Tuberculosis. J Comput Assist Tomogr. 2009;33(6):956-60.

12. Chung MJ, Lee KS. Drug-Sensitive Tuberculosis, Multidrug-Resistant Tuberculosis, and Nontuberculous Mycobacterial Pulmonary Disease in Nonaids Adults: Comparisons of Thin-Section CT Findings. Eur Radiol. 2006;16:1934-41.

13. Song Y, Park CM. Drug-Resistant Tuberculosis Including Multidrug Resistant and Extensively Drug Resistant Tuberculosis : Their Clinical Significance and Features , Imaging Characteristics. Eur Soc Radiol. 2011;C-0855:1-22.

14. Navarro Ballester A. Computed Tomography Features of Multi- Drug-Resistant Pulmonary Tuberculosis in Non-HIV-Infected Patients. Smgroup, Pamplona. 2016;1-12.

15. Jihoon Cha, Ho Yun Lee, Kyung Soo Lee, WonJung Koh, O Jung Kwon, Chin A Yi, Tae Sung Kim MJC. Radiological Findings of Extensively DrugResistant Pulmonary Tuberculosis in Non-AIDS Adults : Comparisons with Findings of MultidrugResistant and. Korean J Radiol. 2009;10(June):20716.

16. Lee ES, Park CM, Goo JM, Yim J, Kim H, Lee PHJ, et al. Computed Tomography Features of Extensively Drug-Resistant Pulmonary Tuberculosis in Non HIV-Infected Patients. J Comput Assist Tomogr. 2010;34(4):559-63.

17. Palmero D, Ritacco V, Ambroggi M, Natiello M, Barrera L, Capone L, et al. Multidrug-Resistant Tuberculosis in HIV-Negative Patients, Buenos Aires, Argentina. Emerg Infect Dis. 2003;9(8):9659.

18. Zahirifard S. The Radiological Spectrum of. 1999;1999-2004.

19. Dheda K, Booth H. Lung Remodeling in Pulmonary Tuberculosis. J Infect Dis. 2005;192(7):1201-1210. 